\title{
Editorial
}

\section{The role of cognitive behavioural therapy in living well with COPD}

The objectives of this editorial are to explore the importance of psychological comorbidity in chronic obstructive pulmonary disease (COPD), potential treatment options and why clinicians do not address this important issue.

COPD is a common, progressive respiratory condition, affecting millions of people worldwide [1] At an individual level COPD often leads to gradual progressive breathlessness and disability, punctuated by episodes of worsening of symptoms. These exacerbations are often life threatening, necessitating admission to hospital. The principal physiological abnormality is airway obstruction. Traditionally the mainstay of treatment has been inhaled medication, aimed at reducing that obstruction, and vast sums of money are spent on inhalers globally every year. While inhaled medication has an important role, there is now increasing recognition of the importance of non-respiratory manifestations of COPD including: fatigue, malaise, muscle wasting, reduced appetite, weight loss, osteoporosis, anxiety and depression. Recent national and international guidelines recognise that good quality, holistic care of COPD should address all aspects of the condition and not merely focus on treatments aimed at improving airway obstruction [1-3]

Until recently one of the most important aspects of COPD, its psychological impact, was barely recognised, let alone, addressed [4, 5]. Psychological ill health is very common in COPD: $60 \%$ of patients with COPD have symptoms of anxiety and $40 \%$ have symptoms of depression [6]. Anxiety and depression have a significant impact on breathlessness, physical functioning, quality of life, exacerbation rates, use of healthcare resources, length of hospital stay, readmission rates and mortality [7-10]. Both anxiety and depression are, of course, enormously detrimental to quality of life in their own right; they also interact with and amplify physical symptoms of COPD. Hyperventilation and panic can heighten the sensation of breathlessness [11] and a vicious cycle can develop. Patients with psychological difficulties are less able to manage symptoms [12], are less likely to be physically active [13] or attend pulmonary rehabilitation, an evidence based intervention, which is a key strategy for people with chronic respiratory conditions [14]. However, if recognised, the psychological impact of COPD is very treatable.

\section{How can we treat psychological difficulties in COPD?}

For many years the integration of physical and mental health has been poor. Recent studies have demonstrated the value of psychological therapy, with promising results for cognitive behavioural therapy (CBT) in the treatment of anxiety and depression in COPD $[10,15,16]$. CBT is an evidencebased, patient-centred, individualised, structured psychological treatment, which aims to understand patients' current difficulties. CBT explores the

@ERSpublications

Psychological ill health is very common in COPD; CBT may be a key step towards improving the care of COPD patients http://ow.ly/fb8j30onfPj

Cite as: Heslop-Marshall K Burns $\mathrm{G}$. The role of cognitive behavioural therapy in living well with COPD. Breathe 2019; 15: 95-97. 
links between a patient's situation, physical symptoms, thoughts, emotions and behaviour $[17,18]$. Techniques are directed at tackling current difficulties and teaching the patient skills to identify unhelpful thinking or behaviour which might be causing vicious cycles of anxiety and/or depression. Having a clearer understanding of the patient's problems can then lead to identifying ways to overcome these difficulties and identify strategies that can help improve the patient's quality of life.

A starting point for patients with respiratory problems is to identify what triggers a patient's breathlessness: physical (e.g. exertion) and/or psychological factors (fear or panic). You can then work with the patient to develop a self-management plan to address their physical and psychological difficulties [19]. Many cognitive and behavioural techniques enhance medical care, for example, identifying and addressing unhelpful thinking (e.g. I need oxygen because I am breathless), planning and pacing activities, breathing techniques, distraction and relaxation can all help breathlessness alongside inhaled therapy. Recently, a large randomised controlled trial of CBT in COPD found that respiratory nurses were able to learn and deliver CBT techniques as a brief intervention to patients with COPD and that this improved symptoms of anxiety and reduced use of healthcare resources (emergency department attendance and hospital admissions) [20, 21].

Due to the high level of psychological comorbidity, at the very least, healthcare professionals need to be able to identify when patients have psychological difficulties and know when to refer on. Patients with all levels of COPD severity and symptoms of anxiety and/ or depression can benefit from CBT [20]. It is crucially important that clinicians are working at a level within their competency skills. It is important to know when it is appropriate for appropriately trained respiratory healthcare professionals to undertake CBT and when it is not. To provide safe and effective psychological care we must ensure that the right person with the right skills is providing the treatment. For patients with mild to moderate symptoms of anxiety or depression then it is clearly feasible for appropriately trained respiratory healthcare professionals to provide a brief CBT intervention [20]. However, for patients with moderate to severe symptoms or those with symptoms indicative of psychiatric disorders, such as generalised anxiety, post-traumatic stress disorder or obsessive compulsive disorder, then referral to mental health services will be required [22]. Unfortunately, clinicians often avoid addressing the issue at all.

\section{So why is it taking so long for clinicians to address this issue?}

Three barriers are identifiable. First, there is probably a failure to recognise the scale of the problem. Doctors might have observed evident symptoms of anxiety in a few cases and assumed the problem related to the psychological makeup of the individual. Yet a moment's reflection in anyone with even a basic understanding of the human condition would have led to the acknowledgement that being "unable to breathe" is one of the most frightening and panic-inducing events a human being can experience. Patients (if you care to ask them about it) will tell you they can feel as if they "are about to die". Panic is understandably common during episodes of severe breathlessness. In fact, the prevalence of panic disorder in patients with COPD is up to 10 times greater than the overall population prevalence and panic attacks are commonly experienced [23].

Secondly, there has been a lack of acceptance that, as clinicians looking after COPD patients, the issue of psychological ill health was part of our remit. It is not simply that we did not feel we had the requisite skill set to deal with the problem, we perhaps felt that the outcomes of treatment, e.g. reduced levels of anxiety, were the concern of others and bore no relationship to the outcomes we were interested in: reducing breathlessness and hospital admission. However, CBT has now been shown to reduce anxiety and breathlessness [10, 21] and admissions [20].

Thirdly, the final barrier is one of access to the appropriate therapy as availability of trained therapists is scarce. Given the shortage of psychologists, the model for delivering psychological care, in the form of CBT, to respiratory patients described by Heslop-Marshall et al. [20] in their real-world study would seem not only opportune but apposite. If CBT skills could be acquired by respiratory clinicians (nurses, physiotherapists or even doctors) it could create a super-therapist with a highly relevant suite of knowledge and skills to integrate physical and psychological care in a truly holistic way; a therapist, perhaps uniquely placed to not only deal with the separate issues of physical symptoms, such as breathlessness, and psychological symptoms, such as anxiety, but also to understand their relationship to one another and begin the untangling process.

\section{Conclusion}

Front-line clinicians are often aware that patients experience symptoms of anxiety and depression. After all, we'd all acknowledge that breathlessness is a very frightening symptom that most respiratory patients experience. What has hitherto been unrecognised is that addressing psychological distress will also help achieve important physical outcomes, such as reduced breathlessness and fewer hospital admissions.

There is increasing evidence that integrating mental and physical care for people with long-term conditions can improve both physical and mental health and reduce costs [24]. The question of how to incorporate CBT into routine care has been addressed in a real-world study [8]. My colleagues and I have 
demonstrated that it is feasible to train respiratory nurses to deliver CBT for patients. This care model brings significant benefits to patients and cost savings to healthcare services [20]. As Yohannes [8] has suggested, CBT may be a key step towards improving the care of COPD patients. The challenge facing clinicians, managers and commissioners is to implement this model into routine clinical care and have a clear pathway to refer more complex psychological problems on to mental health teams.

\section{Affiliations}

\section{Karen Heslop-Marshall, ${ }^{1,2}$, Graham Burns ${ }^{1}$}

${ }^{1}$ Dept of Respiratory Medicine, Royal Victoria Infirmary, Newcastle upon Tyne, UK. ${ }^{2}$ Institute of Health and Society, Medical School, Newcastle University, Newcastle upon Tyne, UK.

\section{Conflict of interest}

K. Heslop-Marshall reports grants from National Institute for Health Research, personal fees from GSK, Boehringer Ingleheim and Astra Zeneca (for lectures on CBT in COPD), personal fees from Pfizer (for advisory board and lectures on CBT), during the conduct of the study; she is Director of Pivotal Healthcare Training Ltd (a CBT training company), outside the submitted work. G. Burns has nothing to disclose.

\section{References}

1. Global Initiative for Chronic Obstructive Lung Disease. Global, Strategy for the Diagnosis, Management, and Prevention of Chronic Obstructive Pulmonary Disease Report (2019 report). https://goldcopd.org/wp-content/uploads/2018/11/GOLD2019-v1.7-FINAL-14Nov2018-WMS.pdf Date last accessed: March 17, 2019.

2. National Institute for Health and Care Excellence. Chronic obstructive pulmonary disease in over $16 \mathrm{~s}$ : diagnosis and management. www.nice.org.uk/guidance/ng115/resources/ chronic-obstructive-pulmonary-disease-in-over-16s-diagnosisand-management-pdf-66141600098245 Date last accessed: March 17, 2019. Date last updated: December 05, 2018.

3. National Institute for Health and Care Excellence. Chronic obstructive pulmonary disease overview. https://pathways. nice.org.uk/pathways/chronic-obstructive-pulmonary-disease Date last accessed: March 17, 2019.

4. Yohannes AM, Wilgoss TG, Baldwin RC, et al. Depression and anxiety in chronic heart failure and chronic obstructive pulmonary disease: prevalence, relevance, clinical implication and management principles. Int J Geriatr Psychiatry 2010; 12 : 1209-1221.

5. Baraniak A, Sheffield D. The efficacy of psychologically based interventions to improve anxiety, depression and quality of life in COPD: a systematic review and meta-analysis. Patient Educ Counsel 2011; 83: 29-36.

6. Heslop-Marshall K, De Soyza A. Are we missing anxiety in people with chronic obstructive pulmonary disease (COPD)? Ann Depress Anxiety 2014; 1: 1023.

7. Maurer J, Rebbapragada V, Borson S, et al. Anxiety and depression in COPD: current understanding, unanswered questions, and research needs. Chest 2008; 134: Suppl, 43S-56S.

8. Yohannes AM. Nurse-led cognitive behavioural therapy for treatment of anxiety in COPD. ERJ Open Res 2018; 4: 00221-2018.

9. Gudmundsson G, Gislason T, Janson C, et al. Risk factors for rehospitalisation in COPD: role of health status, anxiety and depression. Eur Respir J 2005; 26: 414-419.

10. Livermore N, Dimitrice A, Sharpe L, et al. Cognitive behaviour therapy reduces dyspnoea ratings in patients with chronic obstructive pulmonary disease (COPD). Respir Physiol Neurobiol 2015; 216: 35-42.

11. Livermore N, Sharpe L, McKenzie D. Catastrophic interventions and anxiety sensitivity as predictors of panic spectrum psychopathology in chronic obstructive pulmonary disease. J Psychosom Res 2012; 72: 388-392.

12. Thew GR, MacCallam J, Salkovskis PM, et al. Developing and evaluating psychological provision in the acute hospital setting for patients with chronic respiratory disease. Cogn Behav Ther 2017; 10: e5.

13. Yohannes AM, Alexopoulos GS. Depression and anxiety in patients with COPD. Eur Respir J 2014; 23: 345-349.

14. Bolton CE, Bevan-Smith EF, Blake JD, et al. British Thoracic Society Guidelines on pulmonary rehabilitation in adults. Thorax 2013; 68: Suppl. 2, ii1-ii30.

15. Cully JA, Stanley MA, Petersen NJ, et al. Delivery of brief cognitive behavioural therapy for medically ill patients in primary care: a pragmatic randomised clinical trial. J Gen Intern Med 2017; 32: 1014-1024.

16. Usmani ZA, Carson KV, Heslop K, et al. Psychological therapies for the treatment of anxiety disorders in chronic obstructive pulmonary disease. Cochrane Database Syst Rev 2017; 3: CD010673.

17. National Institute of Clinical Excellence. Depression in adults with a chronic physical health problem: recognition and management. www.nice.org.uk/guidance/cg91/resources/ depression-in-adults-with-a-chronic-physical-health-problemrecognition-and-management-pdf-975744316357 Date last accessed: March 17, 2019. Date last updated: Oct 28, 2009.

18. National Institute for Health and Clinical Excellence. Generalised anxiety disorder and panic disorder in adults: management. www.nice.org.uk/guidance/cg113/resources/ generalised-anxiety-disorder-and-panic-disorder-in-adultsmanagement-pdf-35109387756997 Date last accessed: March 17, 2019. Date last updated: January 26, 2011.

19. Heslop-Marshall K. Using cognitive behavioural therapy techniques in COPD. Pract Nurs 2018; 29: 594-597.

20. Heslop-Marshall K, Baker C, Carrick-Sen D, et al. Randomised controlled trial of cognitive behavioural therapy in chronic obstructive pulmonary disease. ERJ Open Res 2018; 4: 00094-2018.

21. Howard C, Dupont S. The COPD breathlessness manual: a randomised controlled trial to test a cognitive-behavioural manual versus information booklets on health service use, mood and health status, in patients with chronic obstructive pulmonary disease. NPJ Prim Care Respir Med 2014; 24: 14076.

22. Tselebis AT, Pachi A, Ilias I, et al. Strategies to improve anxiety and depression in patients with COPD: a mental health perspective. Neuropsychiatr Dis Treat 2016; 12: 297-328.

23. Livermore N, Sharpe L, McKenzie D. Panic attacks and panic disorder in chronic obstructive pulmonary disease: a cognitive behavioural perspective. Respir Med 2010; 104: 1246-1253.

24. Foley T. Bridging the Gap: the financial case for a reasonable rebalancing of health and care resources. London, Royal College of Psychiatrists, 2013. 